JOURNAL OF THE SOUTH AFRICAN INSTITUTION OF CIVIL ENGINEERING

Vol 57 No 3, September 2015, Pages 26-34, Paper 1156

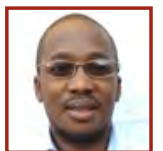

MOKGELE MATHEBA (Pr Tech Eng) focuses on pavement engineering and materials investigation, implementation and monitoring of labour-based road projects, as well as project management related to laboratory testing. He holds the qualifications BTech (Transportation Engineering) and MTech (Civil) obtained from the former Technikon Pretoria and Tshwane University of Technology respectively. He is currently the operations manager for Africa at Geostrada Engineering Materials Laboratory a business unit of Aurecon. He is also an external moderator for the BTech courses at the University of South Africa.

\section{Contact details:}

Geostrada Materials Engineering Laboratory

PO Box 11126, Hatfield, 0028, South Africa

T: +27 (0)12 432 0500, E: mokgelem@geostrada.co.za

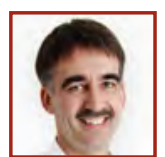

PROFWYNAND STEYN (Pr Eng, MSAICE) researches vehicle-pavement interaction, accelerated pavement testing, and pavement materials and instrumentation. He obtained a PhD in Civil Engineering from the University of Pretoria in 2001. He spent 19 years with the CSIR (Council for Scientific and Industrial Research) in various positions, and is currently professor of civil engineering (focusing on road pavement-related subjects) at the University of Pretoria. Professional activities include academic and industry research in the areas of pavement engineering, vehicle-pavement interaction and pavement materials. He has authored and co-authored 20 journal papers, 17 book chapters and 74 conference papers. He is Associate Editor of the International Journal for Pavement Engineering and has a B3 NRF rating.

\section{Contact details:}

Department of Civil Engineering, University of Pretoria

Private Bag X20, Hatfield, 0002, South Africa

T: +27 (0)12 420 2171, E: wynand.steyn@up.ac.za

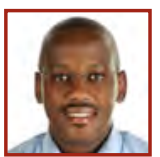

JONES MOLOISANE (Pr Tech Eng, MSAICE) has a research interest in low-volume roads, road construction materials and soil stabilisation. He holds the qualifications MTech (Civil) cum laude and MSC (Appl Sci) obtained from the former Technikon Pretori and University of Pretoria respectively. He is currently lecturer (focusing on transportation engineering technology, and construction contract management and administration-related subjects) in the Department of Civil Engineering at the Tshwane University of Technology, South Africa. He is also currently the chairman of the board of directors and shareholder of Virtual Consulting Engineers (Pty) Ltd, and a director and shareholder of Delta Built Environment Consultants (Pty) Ltd and Science Ignite.

\section{Contact details:}

Department of Civil Engineering, Tshwane University of Technology Private Bag X680, Pretoria, 0001, South Africa

$\mathrm{T}:+27$ (0)12 382 5221, E: moloisaneri@tut.ac.za

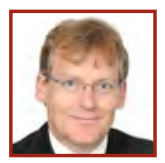

DRTERENCEMILNE (Pr Eng, MSAICE) has extensive experience in road and rehabilitation design documentation and supervision, contract administration, implementation of rural water and roads upliftment projects in developing areas, and the management of large infrastructure projects, including engineering, procurement, and construction management (EPCM). He graduated from the University of Witwatersrand with a BSC (Eng) in 1985, after which he commenced employment with Van Wyk \& Louw (later Africon and now Aurecon), where he is currently technical director and EPCM project manager in capital projects delivery. He obtained his MSc (Eng) in 1993 in the field of Structural Concrete, and his PhD in Engineering in 2004 from the University of Stellenbosch.

\section{Contact details:}

Aurecon

PO Box 74381, Lynnwood Ridge, 0040, South Africa

T: +27 (0)12 427 2000, E: Terence.Milne@aurecongroup.com

\title{
Evaluation of the response behaviour of unconfined cemented materials under dynamic loading
}

\author{
M J Matheba, W J vd M Steyn, R J Moloisane, TI Milne
}

There is a significant increase in traffic loading on most roads in the developing African countries, and South Africa is one of them. Often this increased traffic loading results in the premature failure of pavement structures. Mechanistic-empirical (M-E) design methods based on fundamental principles are better able to accommodate changes in the design environment. The successful use of design methods depends on the accuracy of the input material parameters. Therefore, as design is moving towards M-E design methods, there is a need for the material parameters to reflect the actual pavement response to dynamic loads. The objective of this paper is to report on the investigation of the response of cement-stabilised sub-base layers to dynamic load by evaluating stiffness at a known strain level. This stiffness was compared with those derived from unconfined compressive strength (UCS) tests performed at static load. The strain and stiffness values were also evaluated against compacted density, cement content, moisture content and material type. It was found that stiffness of some of the cement-stabilised sub-base layers may possibly be overestimated through the use of static loads.

\section{BACKGROUND}

\section{Introduction}

Trends in the road transport sector indicate significant increases in the growth of traffic loading, due to an increase in the number of vehicles on all road types in developing countries, such as South Africa (Kekana 2006). The increase in the traffic loading on road pavements leads to increased damage, high maintenance and on-going repair costs, as well as the shortening of the life of the roads. Often traffic loading results in premature failure of roads, with expensive maintenance having to be carried out, and in many cases, even complete reconstruction of failed roads being undertaken (Cottrell et al 2003). The South African road design method is being reviewed by the South African National Roads Agency (SANRAL) (SANRAL 2007), partly to accommodate the increase in traffic loading and traffic volume, so that roads will be able to support these increased loads. The revision of the South African design method for flexible pavements, which focuses on the effect of the increase of traffic loading in the pavement structure, is a long-term project with the aim of improving the existing MechanisticEmpirical (M-E) design methods of flexible pavements (SANRAL 2007). M-E design methods are better able to accommodate changes in the design environment. The success of these M-E design methods depends on the accuracy of the input parameters and the way in which the material parameters are determined (Theyse 2001). Therefore there is a need for material parameters to reflect the actual pavement response under dynamic tyre loads. The main parameters affecting material behaviour include stress, strain and stiffness.

Traffic stress can cause a decrease in the strength of the pavement, as the pavement layers undergo different phases of distress (De Beer 1985; Theyse et al 1996). In real life these pavements and material layers are responding to dynamic traffic loading (De Beer 1990; Theyse 2001). Relatively small decreases in layer strength would reduce the expected structural capacity. This raises uncertainty about the actual structural capacity of pavements, since the stiffness of the sub-base will vary considerably during the construction and completion phases and there would be no clear basis to determine what the 'correct' stiffness of the sub-base layer should be (Jordaan 1994). Therefore there is a need to look at the materials' response to dynamic repetitive loading.

Different vehicle configurations cause different load functions in terms of load level and frequency on a pavement structure (Steyn et al 1999). The following terminology for load case description has been proposed by Steyn et al (1999):

- Static load - load that is independent on time and location 
- Dynamic load - load that is dependent on time and independent of position (load magnitude changes according to some time-based function and the position is static)

- Moving dynamic load - load that is dependent on both the time and position (load magnitude changes according to some time-based function, and position also changes).

Real traffic causes moving dynamic loads, while dynamic load is mainly used in the search to simplify the understanding of pavement response. The response analysis of the pavement layers' stiffness should be dictated by the type of load applied. Consequently, dynamic pavement response analysis should be performed for time-dependent loading.

The objective of this paper is to report on the investigation of the response of the cement-stabilised sub-base layers to dynamic loading. The investigation was carried out by evaluating the changes in stiffness at known strain level, and these were compared to the stiffness from dynamic loads derived from the unconfined compressive stress (UCS) test. This work is based on an extensive laboratory study where two materials (ferricrete and norite) were stabilised with cement and tested in both wet and dry conditions using a repetitive loading test method, as reported by Matheba (2013).

\section{Analysis of cement-stabilised sub-base layers}

The response of each layer in a pavement structure to traffic loading or environmental conditions affects the response of the other layers. A cement-stabilised layer normally becomes stiffer or gains more strength mainly when the cement content in the material is increased. Normally the cement-stabilised layer develops shrinkage cracks resulting from drying and thermal stress of the cement-stabilised layer, which is not related to traffic loading but to the hydration caused by the cement in the material. With increased traffic loading the effective stiffness, which is defined as the ratio of the rate change of stress with the elastic strain of the layer, will decrease (De Beer 1990). The maximum tensile strain at the bottom of the layer (which controls the effective fatigue life of the pavement) and the vertical compressive stress $(\sigma)$ on top of the cemented layer (controlling its crushing life) should be monitored to evaluate the life of the layer. In practice the maximum tensile strain is referred to as the strain-at-break of the material to normalise the working strain in the stiffness.

Strain-at-break refers to the strain when a cement-stabilised layer is loaded beyond

Table 1 Determination of layer stiffness (Van Wijk et al 2007)

\begin{tabular}{|c|c|}
\hline Stiffness & Calculation/estimation method \\
\hline Existing unbound layers & $\begin{array}{l}\text { Tri-axial testing* } \\
\text { Back-calculation from deflections }{ }^{* * *} \text { (i.e. deflection bowl parameters) }\end{array}$ \\
\hline New unbound layers & $\begin{array}{l}\text { Primary reliance on tri-axial testing* } \\
\text { Soil classification and simple tests* }\end{array}$ \\
\hline Existing cemented soils & $\begin{array}{l}\text { Estimate from unconfined compressive strength (UCS)* } \\
\text { Back-calculation from deflections** (i.e. deflection bowl parameters) }\end{array}$ \\
\hline New cemented soils & $\begin{array}{l}\text { Estimate from unconfined compressive strength }(\mathrm{UCS})^{*} \\
\text { Use tri-axial test* } \\
\text { Estimate flexural strength from beam test* }\end{array}$ \\
\hline \multicolumn{2}{|c|}{$\begin{array}{l}\text { Laboratory-related test that is used to destructively assess the specimen's failure, in order to understand } \\
\text { its material behaviour under different loads. } \\
\text { Field-related test that is used to non-destructively assess the structural properties of a flexible } \\
\text { pavement }\end{array}$} \\
\hline
\end{tabular}

certain limits and micro cracks develop between coarse particles, and the layer fails to recover to its original position, resulting in permanent deformation. Previous studies have found that micro cracks start to occur at $35 \%$ of actual strength and $25 \%$ of strainat-break under repeated loading (CSRA 1986 TRH 13; De Beer 1990; Jones et al 2001). The strain-at-break is deduced from flexural strength tests in the laboratory. The practice of using the strain-at-break of the material to normalise the working strain in the stiffness reduction is in doubt since significant discrepancies in the strain-at-break results from different research laboratories have been noted (Theyse et al 2007). The response of a cement-stabilised layer to an applied load is highly affected by moisture content, compaction and cement content.

Repetitive loading increases fatigue cracking of the cement-stabilised layer which results in the crushing of the layer over time (De Beer 1990). Once the layer is crushed the stiffness is reduced to a natural material layer. At this stage the layer is more sensitive to environmental conditions, such as moisture.

\section{Design material tests}

Different types of material design test methods are used to determine input parameters in the M-E design method. These material design test methods are used to obtain the materials' strength for the different layers in the pavement structure (Van Wijk et al 2007). The stiffness of various pavement layers is estimated by means of destructive or non-destructive methods as indicated in Table 1.

\section{Unconfined compressive strength (UCS) method}

The UCS measures the strength of the stabilised material. The UCS test method determines only the maximum compressive strength of any stabilised material under static loading. The maximum compressive strength value is used to predict the effective strength of cemented layers.

\section{Flexural strength (beam test) test method} The composite of tensile strength and tensile strain capacity of a material sample are determined through its flexural strength (Natt \& Joshi 1984). The method is reliable for determining tensile strains, as it can be measured from a bending level of a material sample. The strain at break is measured under static load, but the elasticity of the material cannot be determined, because the sample is continuously under load. In considering a field sub-base layer response to repetitive load, there is a need to incorporate it for determination of elastic strain of the material response to load.

\section{Falling weight deflectometer (FWD) test method}

The FWD test method produces a dynamic impulse load that simulates a moving wheel load. Complete deflection bowls are used in an iterative procedure, known as backcalculation, to estimate the pavement layer effective stiffness. The goal of the backcalculation process is to estimate a set of layer effective stiffnesses that best match the measured deflections at all locations where deflections are measured.

\section{EXPERIMENTAL PROCEDURE}

The dynamic loading was developed to simulate field conditions where the cementstabilised pavement structures and layers are exposed to similar circumstances. The aim is to have a better understanding of the performance of the cemented layers under repeated loading. A dynamic loading method was developed on the basis of the UCS with regard to the preparation of the cementstabilised specimen only. For the testing of samples, a repetitive load was applied on the 


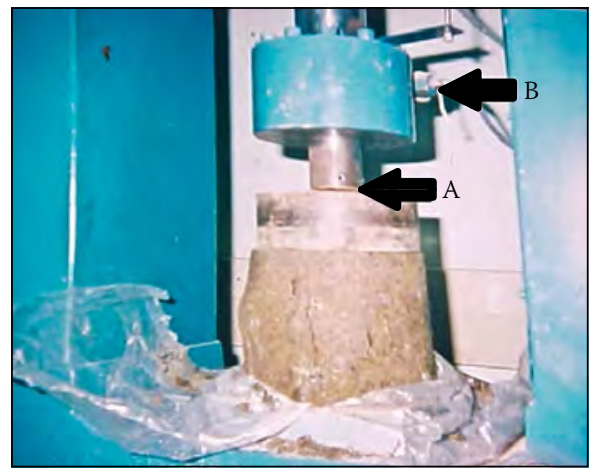

Plate 1 Cemented specimen under dynamic loading

specimen of the cement-stabilised material to measure both the stress and micro-strain for deducing an effective stiffness of the stabilised material layer.

\section{The use of dynamic load and its specifications}

Dynamic loading equipment consists of a $50 \mathrm{~mm}$ diameter piston that applies a vertical load on the specimen. A spacer of $127 \mathrm{~mm}$ in diameter and $3.8 \mathrm{~mm}$ in thickness, that weighs $4.25 \mathrm{~kg}$, is placed on top of the specimen during the testing process. The plate allows for equal distribution of the load at the point where it reaches the specimen, as shown in Plate 1.

There are two electronic sensors - sensor A measures the specimen's micro-strain as a function of a displacement, and sensor B measures the actual applied stress as a function of the load on a specimen. The dynamic load testing equipment is programmed to apply an initial load of $1.8 \mathrm{kN}$ per 1.5 second on the specimen. This load induces a stress equivalent of $100 \mathrm{kPa}$. The stress of $100 \mathrm{kPa}$ is applied for 2500 load repetitions before it increases the stress in $100 \mathrm{kPa}$ increments. De Beer et al (1999) found that a combination of traffic, such as buses, light commercial vehicles and trucks, contributes to pavement deterioration differently because of their differing axle loads, and the load from slow-moving traffic induces more stress levels as more loads are being applied to the pavement. Therefore a rate of 1.5 second intervals was established based on the concept that if vehicles travel at $60 \mathrm{~km} / \mathrm{h}$ at intervals of $25 \mathrm{~m}$, it will take 1.5 seconds for the second vehicle to reach the point where the first vehicle had been. A 0.008 second tyre/pavement contact stress used in the pavement analysis (De Beer et al 1999) in the upper layer up to $300 \mathrm{~mm}$ (Steyn \& Sadzik 2007) was for the vehicle travelling at a higher speed. This assumption was based on the research conducted for the measurement of tyre-to-pavement contact stress, and is generally described as Stress-in-Motion (SIM) technology (De Beer et al 1999). Stress was determined using the expression in Equation 1:

$$
\begin{aligned}
& \text { Stress }(\sigma)=\frac{\text { Applied load }}{\text { Area which load is applied }} \\
& \text { to on the surface }
\end{aligned}
$$

Where:

$$
\begin{aligned}
\text { Applied load }= & k N \\
\text { Area }\left(m^{2}\right)= & r^{2} \times 3.41 \text { (radius of a } \\
& \text { specimen multiplied by } \\
& 3.41 \text { ) } \\
\text { Radius }(r)= & \text { radius of a specimen }(m)
\end{aligned}
$$

A permanent displacement of the cemented specimen under repetitive load was measured for every load applied. For every phase, the average displacement was determined and used to calculate the material strain by means of the expression in Equation 2:

$$
\text { Microstrain }=\frac{h}{H}
$$

Where:

$$
\begin{aligned}
h= & \text { average displacement }(\mathrm{mm}) \\
H= & \text { height of the specimen which is } \\
& 127 \mathrm{~mm}
\end{aligned}
$$

The behaviour of the cemented specimen was observed by noting the change in strain caused by loads applied dynamically until it failed, while stiffness was calculated at each phase. A recovered displacement of the cemented specimen under repetitive load was measured at every load applied. For every phase, the average displacement was determined and used to calculate the material strain.

Environmental influences, such as regional moisture conditions, play an important part in the performance of the cementstabilised layer. This factor may not have full impact to cement-stabilised layers without a load application since the environmental factor is a secondary variable. The soil samples were tested under two environmental conditions:

- Dry condition - the cemented specimen was not covered for moisture loss during repetitive load testing, irrespective of how long the test took to complete. (Moisture loss from a specimen was only monitored by the material's response to load).

- Wet condition - the specimen was wrapped in impermeable plastic to prevent any evaporation occurring from the cemented specimen when the repetitive loading test was applied.

\section{Selected materials}

Two types of materials, i.e. ferricrete and norite from the Gauteng Province in South
Africa, and one cement agent, i.e. CEM II A-L $32.5 \mathrm{~N}$ were used to evaluate the strength characteristics of cement-stabilised materials. The name ferricrete is derived from the combination of ferruginous and concrete (Brink 1985). Weathered norite material is a sub-division of igneous rock. It is largely composed of calcium-rich plagioclase laboradorite and pyroxene (Brink 1985). These materials are commonly used in the construction of roads, especially in the sub-base layers in the Gauteng Province and surrounding areas (Sadzik 2004), and their performance has been extensively studied. The yellowishbrown ferricrete material was sampled from the borrow-pit situated along Road K109 near Brakpan and Benoni in the Gauteng Province. This material was used in 2001 as a sub-base material in the upgrading construction of Road K109. Ferricrete material is an iron-oxide cemented regolith material. When ferricrete material is mixed with cement and water, it absorbs water very quickly during the hydration process and produces calcium hydroxide, which tends to cause carbonation. This leads to a reduction in strength in the cement-stabilised layer. The weathered norite material was sampled from a borrow-pit situated east of the Bakwena Platinum freeway, near to the Bakwena Platinum freeway/Bela Bela intersection on National Route 1 (N1) in Pretoria, Gauteng Province. This material was used in 2001 as a sub-base material in the construction of the Bakwena Platinum freeway (National Route $4(\mathrm{~N} 4)$ ), which runs from the N1/Sefako Makgatho Drive intersection to the Botswana border.

Common cement, CEM II A-L 32.5N, which complies with the South African Bureau of Standards (SABS) EN197 (now South African National Standards (SANS) 50197-1) was used as a cementing stabiliser (SABS 2001). This type of cement was chosen as it is a product that has been modified to accommodate environmental effects such as temperature (Paige-Green \& Netterberg 2004). CEM II A-L $32.5 \mathrm{~N}$ cement has been used successfully in many recent projects in South Africa. It consists of fly ash (to develop strength in the material) and a small amount of lime (to reduce plasticity in the material).

Ordinary tap water without dissolved salts was used to mix the samples in preparation for determining the natural properties of materials and the preparation of cemented specimens. Contaminated water was avoided, because mineral salts and impurities in the water affect the chemical properties of cement-stabilised materials.

The laboratory test on grain-size distribution, Atterberg limits and California bearing ratio (CBR) were conducted on these ferricrete and norite materials in accordance 


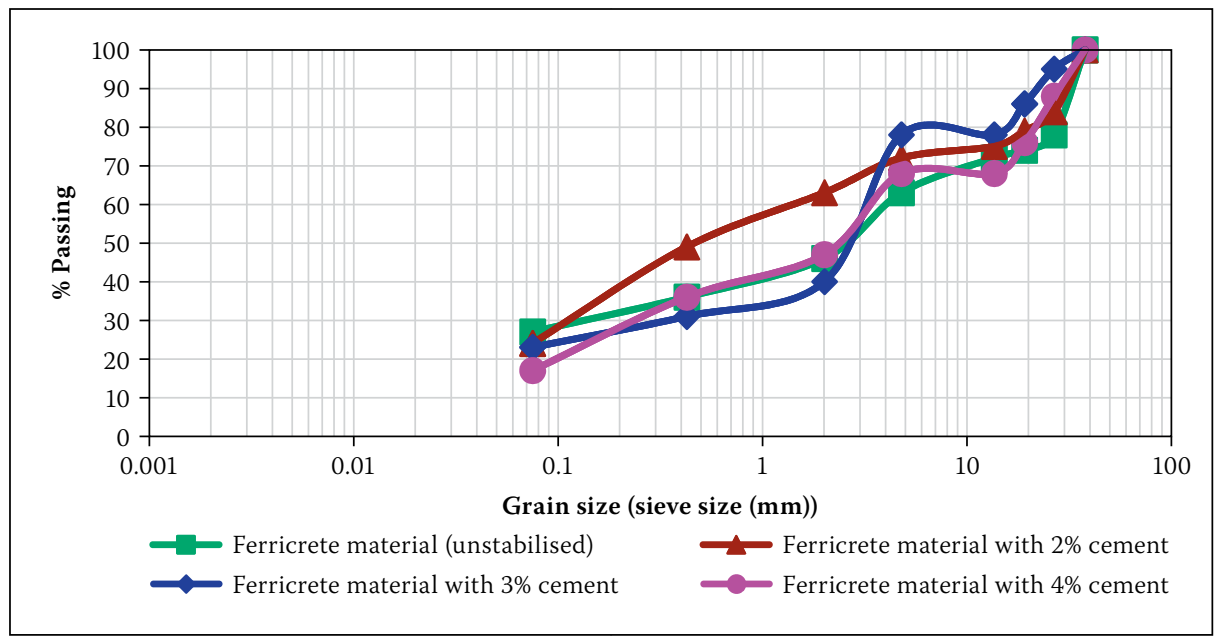

Figure 1 Grain size distribution of the unstabilised ferricrete material and the ferricrete material stabilised with $2 \%, 3 \%$ and $4 \%$ cement content

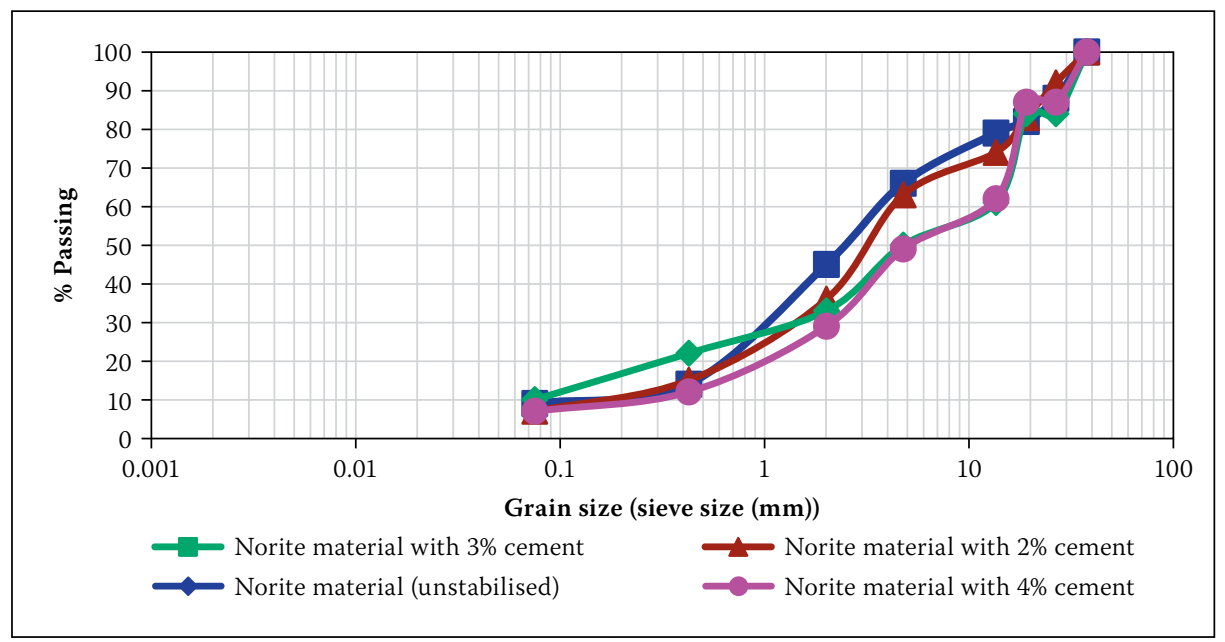

Figure 2 Grain size distribution of the unstabilised norite material and the norite material stabilised with $2 \%, 3 \%$ and $4 \%$ cement content

Table 2 Material properties of the ferricrete material

\begin{tabular}{|c|c|c|c|c|}
\hline \multirow[b]{2}{*}{ Properties } & \multicolumn{4}{|c|}{ Ferricrete material } \\
\hline & $\begin{array}{c}\text { Unstabilised } \\
\text { material }\end{array}$ & $\begin{array}{l}\text { Stabilised } \\
\text { with } \\
2 \% \text { cement }\end{array}$ & $\begin{array}{l}\text { Stabilised } \\
\quad \text { with } \\
3 \% \text { cement }\end{array}$ & $\begin{array}{l}\text { Stabilised } \\
\quad \text { with } \\
4 \% \text { cement }\end{array}$ \\
\hline Grading modulus (GM) & 1.91 & 1.64 & 2.06 & 2.00 \\
\hline Initial consumption of cement (ICC) (\%) & 4 & - & - & - \\
\hline Liquid limit (LL) (\%) & 28 & 26 & 19 & 14 \\
\hline Plasticity index (PI) (\%) & 11 & 8 & 3 & 1.5 \\
\hline Maximum dry density (MDD) $\left(\mathrm{kg} / \mathrm{m}^{3}\right)$ & 2016 & - & - & - \\
\hline Optimum moisture content (OMC) (\%) & 12.1 & - & - & - \\
\hline \multicolumn{5}{|l|}{ California bearing ratio (CBR) values (\%) } \\
\hline At $90 \%$ Modified AASHTO density & 11 & \multirow{4}{*}{\multicolumn{3}{|c|}{$\begin{array}{l}\text { CBR was done only on the unstabilised } \\
\text { material, and the unconfined compressive } \\
\text { strength (UCS) was done on the cement- } \\
\text { stabilised materials }\end{array}$}} \\
\hline At $93 \%$ Modified AASHTO density & 26 & & & \\
\hline At 95\% Modified AASHTO density & 32 & & & \\
\hline At $97 \%$ Modified AASHTO density & 39 & & & \\
\hline
\end{tabular}

with the TMH 1 (CSRA 1986) standard methods to categorise their natural properties, and were classified in accordance with the TRH 14 (CSRA 1985 TRH 14) classification guidelines.
Two sets of specimens were prepared for every mix of $2 \%, 3 \%$ and $4 \%$, compacted at 95\% and $100 \%$ Modified AASHTO density respectively, and a set of three specimens was prepared to serve as a control test. The cement-stabilised specimens were prepared according to the conventional preparation of the UCS specimen method to determine their behaviour as per TMH 1 (CSRA 1986). Both the $95 \%$ and the $100 \%$ Modified AASHTO density compaction efforts were used in the study to relate the conventional compaction densities of between $95 \%$ and 100\% Modified AASHTO density, as required in the COLTO (COLTO 1998) specifications and various project specifications in South Africa.

\section{EXPERIMENTAL RESULTS AND DISCUSSION}

The effect of compaction and moisture content (monitored only) on stiffness of a cement-stabilised layer was evaluated by comparing the resulting stiffness from dynamic load against the effective stiffness from static load. Grain-size distribution of the unstabilised ferricrete material and the ferricrete material stabilised with $2 \%, 3 \%$ and 4\% cement content are depicted in Figure 1.

More grain fractions of the ferricrete material stabilised with $2 \%, 3 \%$ and $4 \%$ cement content were retained above the $0.075 \mathrm{~mm}$ sieve compared to the unstabilised material. An increase in cement content showed improvement in the ferricrete material. The bond between the grain fractions of the stabilised ferricrete material lower than the $0.475 \mathrm{~mm}$ sieve was improved with the addition of the cement content.

Material properties of the ferricrete material (both the unstabilised and stabilised with $2 \%, 3 \%$ and $4 \%$ cement content) are presented in Table 2.

The unstabilised ferricrete material showed higher plasticity because the disintegration of weathered fine grain of the ferricrete material contributed to higher colloidal clay content of the material. The contribution to higher colloidal clay content by the weathered fine grain of the ferricrete material was also reported by Paige-Green (1989), and Paige-Green and Bam (1995). A grading modulus (GM) of the ferricrete material stabilised with $2 \%$ cement content was unusual to be lower than the unstabilised. This could possibly have been influenced by the higher amount of finer fractions in the sample representation and rapid initial setting due to the high zinc content in the ferricrete material. In theory, the stabilised ferricrete material increases the bonding between the material particles and reduces the fraction of the finer particles. This ferricrete material had a CBR of 32\% at 95\% Modified AASHTO density, which is lower than the G5 but above the G6 soil classification as per TRH 14 (CSRA 1985 TRH 
14) classification guidelines. This could have been caused by the higher optimum moisture content $(\mathrm{OMC})$ in achieving maximum dry density (MDD). This ferricrete material may be sensitive to a high moisture climate when used in pavement layers.

Grain-size distribution of the unstabilised norite material and the norite material stabilised with $2 \%, 3 \%$ and $4 \%$ cement content are depicted in Figure 2.

The bond between the finer fractions smaller than the $0.475 \mathrm{~mm}$ sieve was improved with increases in the cement content. However, the grain fraction at $3 \%$ cement content could have had a poor bond and this could have been caused by the replicating of the quartering of the materials where finer factions were compromised.

Material properties of the norite material (both the unstabilised and stabilised with $2 \%, 3 \%$ and $4 \%$ cement content) are presented in Table 3.

The unstabilised norite material showed lower plasticity because the material was only slightly weathered and more particles were still in a fresh stage. This was confirmed by lesser fraction of the finer material passing the $0.425 \mathrm{~mm}$ sieve. Also, when a small percentage of the cement content of $2 \%$ was added, the finer grains became less sensitive to water and developed into non-plastic. Similar results were observed by Paige-Green and Netterberg (2004) during their earlier work on the use of different types of cement and their effect in strength generation. This confirms that this type of norite material has a low natural plasticity index (PI). This norite material had a CBR of $49 \%$ at $95 \%$ Modified AASHTO density after soaking for four days, which is higher than the minimum requirement of $45 \%$ at $95 \%$ Modified AASHTO density for the G5 material classification as per TRH 14 (CSRA 1985 TRH 14) classification guidelines. This was found to be realistic due to the higher percentage of stone particles which contribute to high resistance in bearing capacity.

The norite and ferricrete materials were classified as per TRH 14 (CSRA 1985 TRH 14) as G5 and G6 natural gravel materials

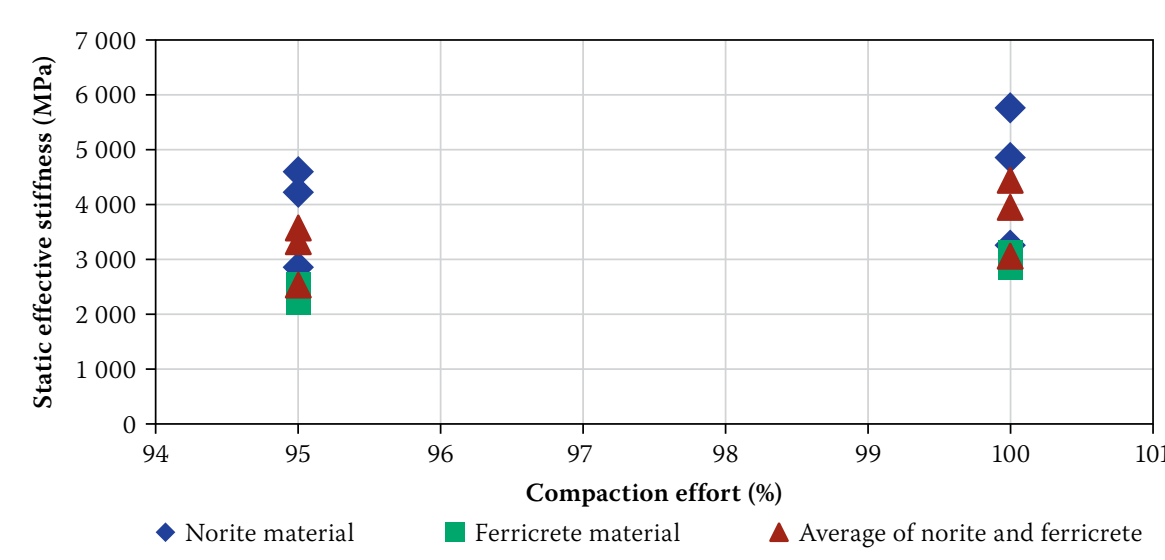

Figure 3 Static effective stiffness of the norite, ferricrete and the average of both the norite and ferricrete materials

respectively. Both materials would be regarded as suitable to be used for stabilisation to a C3 and C4 cemented material. Cemented materials are classified in accordance with the TRH 13 (CSRA 1986 TRH 13) classification guidelines. Following this, specimens of the stabilised materials were prepared.

Three samples were crushed at seven-day age using the conventional UCS method for control tests. An average of the three results was taken as the result of the compressive strength of the 'lot'. These results are presented in Table 4.

The compressive strength of the stabilised ferricrete material was less than the stabilised norite material using conventional UCS. These results are applicable for all cement contents (i.e. $2 \%, 3 \%$ and $4 \%$ ).

\section{Effect of compaction effort}

The static effective stiffness of the norite, ferricrete and the average of both the norite

Table 3 Material properties of the norite material

\begin{tabular}{|c|c|c|c|c|}
\hline \multirow[b]{2}{*}{ Properties } & \multicolumn{4}{|c|}{ Norite material } \\
\hline & $\begin{array}{l}\text { Unstabilised } \\
\text { material }\end{array}$ & $\begin{array}{l}\text { Stabilised } \\
\text { with } \\
2 \% \text { cement }\end{array}$ & $\begin{array}{l}\text { Stabilised } \\
\text { with } \\
3 \% \text { cement }\end{array}$ & $\begin{array}{l}\text { Stabilised } \\
\text { with } \\
4 \% \text { cement }\end{array}$ \\
\hline Grading modulus (GM) & 2.32 & 2.42 & 2.35 & 2.52 \\
\hline Initial consumption of cement (ICC) (\%) & 2 & - & - & - \\
\hline Liquid limit (LL) (\%) & 14 & - & - & - \\
\hline Plasticity index (PI) (\%) & 3 & Non-plastic & Non-plastic & Non-plastic \\
\hline Maximum dry density (MDD) $\left(\mathrm{kg} / \mathrm{m}^{3}\right)$ & 2231 & - & - & - \\
\hline Optimum moisture content (OMC) (\%) & 8.9 & - & - & - \\
\hline \multicolumn{5}{|l|}{ California bearing ratio (CBR) values (\%) } \\
\hline At $90 \%$ Modified AASHTO density & 17 & \multirow{4}{*}{\multicolumn{3}{|c|}{$\begin{array}{l}\text { CBR was done only on the unstabilised } \\
\text { material, and the unconfined compressive } \\
\text { strength (UCS) was done on the cement- } \\
\text { stabilised materials }\end{array}$}} \\
\hline At $93 \%$ Modified AASHTO density & 36 & & & \\
\hline At 95\% Modified AASHTO density & 49 & & & \\
\hline At $97 \%$ Modified AASHTO density & 55 & & & \\
\hline
\end{tabular}

Table 4 Unconfined compressive strength (UCS) results of the ferricrete and norite materials

\begin{tabular}{|c|c|c|c|c|c|c|c|c|c|c|c|c|}
\hline \multicolumn{13}{|c|}{ Unconfined compressive strength (UCS) (kPa) } \\
\hline \multirow{3}{*}{$\begin{array}{c}\text { Compaction } \\
\text { effort } \\
(\%)\end{array}$} & \multicolumn{6}{|c|}{ Ferricrete material (average of three results) } & \multicolumn{6}{|c|}{ Norite material (average of three results) } \\
\hline & \multicolumn{6}{|c|}{ Cement content and standard deviation } & \multicolumn{6}{|c|}{ Cement content and standard deviation } \\
\hline & $2 \%$ & Stdev & $3 \%$ & Stdev & $4 \%$ & Stdev & $2 \%$ & Stdev & $3 \%$ & Stdev & $4 \%$ & Stdev \\
\hline 100 & 760 & 10.5 & 850 & 7.4 & 890 & 8.1 & 960 & 4.8 & 1800 & 5.5 & 2300 & 6.7 \\
\hline 95 & 450 & 5.3 & 550 & 6.4 & 610 & 8.2 & 760 & 5.2 & 1460 & 4.5 & 1660 & 8.2 \\
\hline
\end{tabular}


and ferricrete materials determined at 95\% and 100\% Modified AASHTO density compaction effort are depicted in Figure 3. The test results were obtained from samples that had the same compaction, but contained different cement contents, i.e. 2\%, 3\% and $4 \%$.

The static effective stiffness of the norite, ferricrete and the average of both the norite and ferricrete materials improved with an increase in the densification of the material. The static stiffness increased by $18.8 \%$ (625 MPa) from $95 \%$ to $100 \%$ Modified AASHTO density compaction effort. It is evident that densification keeps soil particles together by reducing voids in the layer which eventually increases the angle of material friction and cohesion. The effective stiffness increases with the increase in cohesion of the material to resist the applied stress of the static load.

\section{Influence of cement content on stiffness response}

The static effective stiffness of all the norite, all the ferricrete and the average of both the norite and ferricrete materials against cement content are depicted in Figure 4.

The static effective stiffness of the norite material increased by $48.4 \%$ from the $2 \%$ to $3 \%$ of the cement content, and by $14.1 \%$ from the $3 \%$ to $4 \%$ of the cement content, while the static effective stiffness of the ferricrete material increased by $7.8 \%$ and $1.5 \%$ from the $2 \%$ to $3 \%$ and $3 \%$ to $4 \%$ of the cement content respectively. Static effective stiffness improved with the increase in cement content. An increase in cement content in both the ferricrete and norite materials improved material strength and increased resistance to cracking and crushing when the material was under load.

The dynamic effective stiffness of the norite, ferricrete and the average of both the norite and ferricrete materials in all wet and dry conditions against cement content are depicted in Figure 5.

The dynamic effective stiffness increased by $41 \%$ and $48 \%$ with an increase from the $2 \%$ to $3 \%$ and the $3 \%$ to $4 \%$ of the cement content, while the static effective stiffness increased by $48 \%$ and $14.1 \%$ with an increase from the $2 \%$ to $3 \%$ and the $3 \%$ to $4 \%$ of the cement content respectively. It can be confirmed that the stiffness response to both dynamic and static loading was directly improved with an increase in cement content, because the cement particles surrounding the granules act as bridges, resulting in bonding and increasing the strength. The rate of increase in shear strength becomes greater as the cement content is increased.

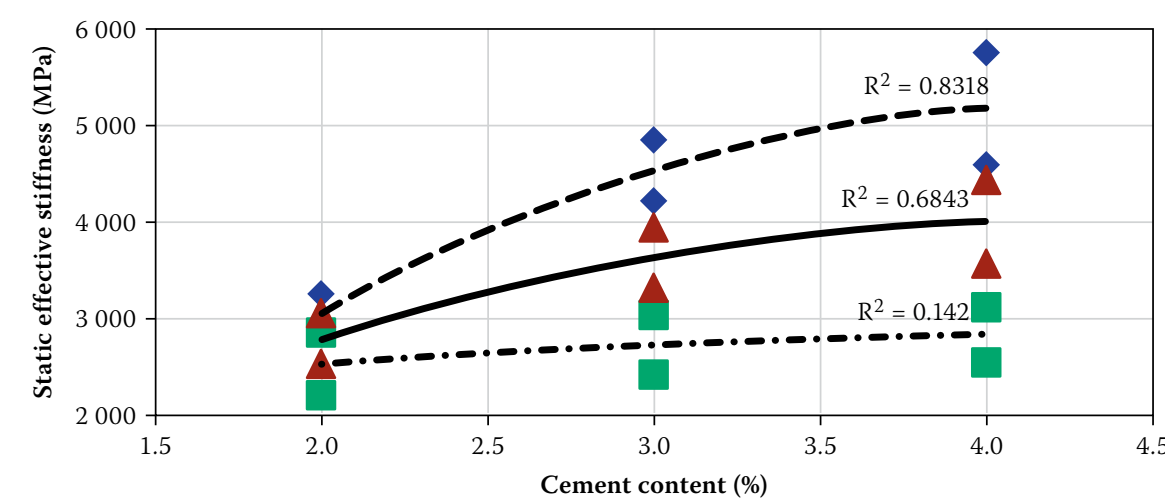

Norite material

Ferricrete material $\Delta$ Average of norite and ferricrete -. Poly. (ferricrete material) - Poly. (norite material) - Poly. (average of norite and ferricrete)

Figure 4 Static effective stiffness of the norite, ferricrete and the average of both the norite and ferricrete materials

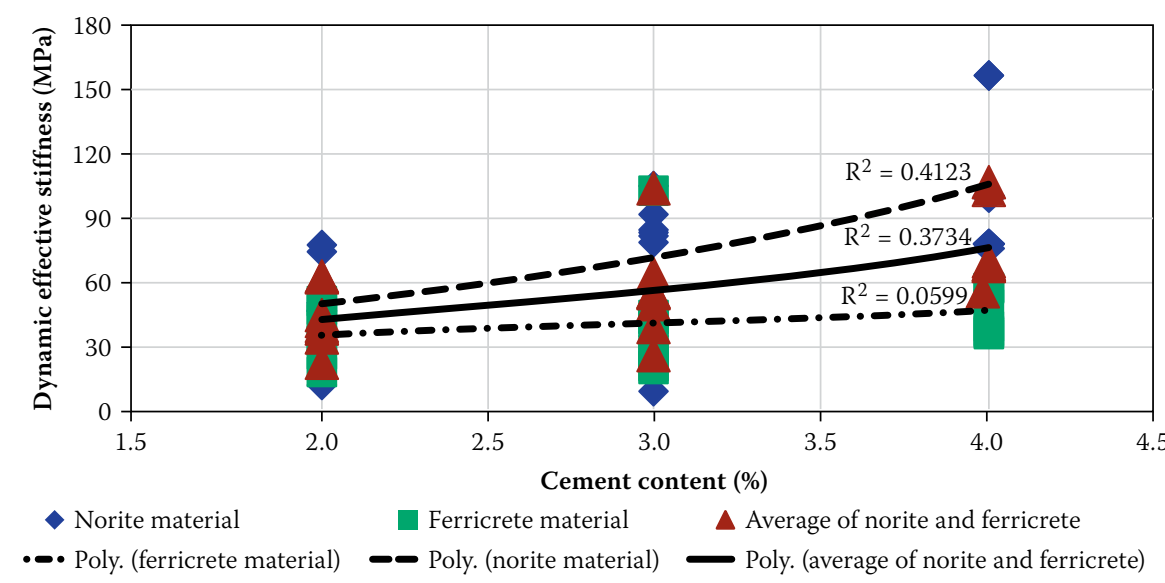

Figure 5 Dynamic effective stiffness of the norite, ferricrete and the average of both the norite and ferricrete materials

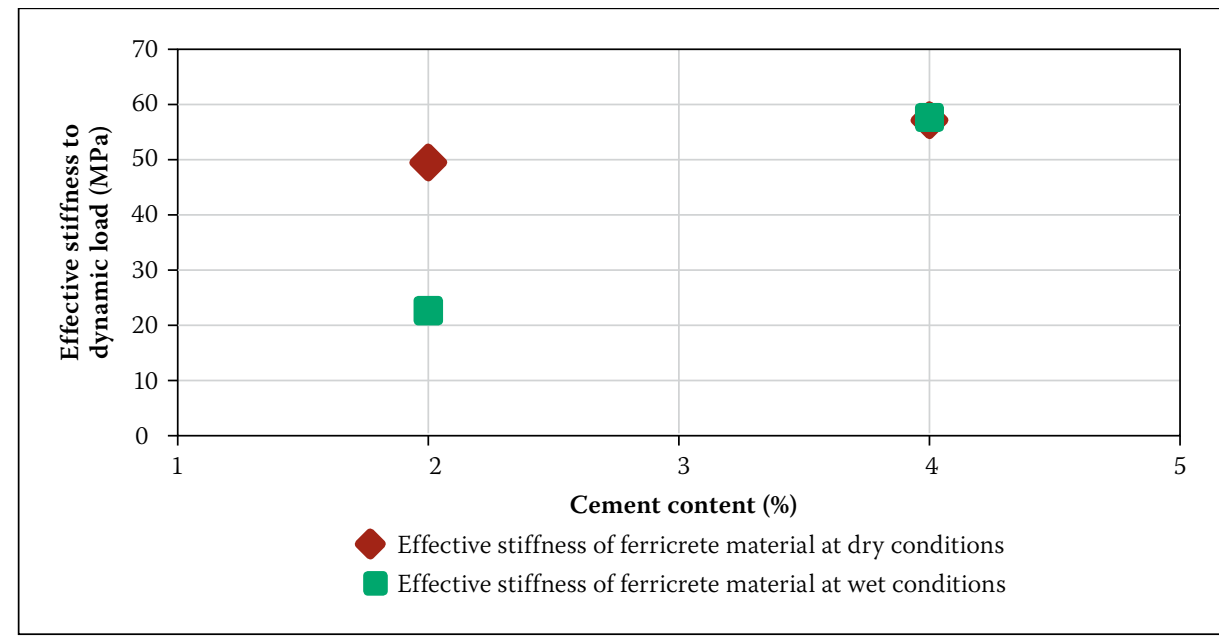

Figure 6 Dynamic effective stiffness at 100\% Modified AASHTO density compaction effort in the variations of the conditions of the stabilised ferricrete material

It was noticed that an increase of $1 \%$ of the cement content on the sub-base layer may increase the effective stiffness response to dynamic load proportionally, irrespective of the type of material or material properties, because the layer damage induced by dynamic load is primarily in the form of extensive micro cracks during the effective fatigue phase.

\section{Effect of moisture on the material}

The sensitivity to variation in moisture of the ferricrete and norite materials was determined by comparing the differences in stiffness in both wet and dry conditions. This was uncontrolled and not monitored, and would depend on the laboratory conditions (temperature and humidity), as well as on the duration of testing. The stiffness of 
the ferricrete material stabilised with $2 \%$ and $4 \%$ under dynamic loading at wet and dry conditions when the material was compacted at $100 \%$ Modified AASHTO density compaction effort, as depicted in Figure 6.

The intention with the two points depicted in Figure 6 was to evaluate the effect of the variation in moisture, rather than to evaluate the quantity of the effect. The dynamic effective stiffness of the ferricrete material stabilised with $2 \%$ cement content showed an improvement of $123 \%$ from $22 \mathrm{MPa}$ to $49 \mathrm{MPa}$ in stiffness when the material deviated from wet to dry conditions. On the other hand, the dynamic effective stiffness of the ferricrete material stabilised with $4 \%$ cement showed no improvement when the material deviated from wet to dry conditions. These results revealed that higher compaction and cementation of the material resulted in better material bonding. This means the material could have a higher capacity to resistance fatigue when the material is under stress. However, the stiffness of the norite material stabilised with $4 \%$ cement showed no improvement when the material was tested at wet to dry conditions. This indicated that this type of material becomes more rigid at maximum compaction effort (100\% Modified AASHTO density) at optimum moisture content (OMC), and possibly at $4 \%$ cement with the resulting material being less sensitive to water and moisture. At that stage, the cement-stabilised material became more cohesive and rigid irrespective of moisture content and resulted in being more resistant to fatigue and cracking under controlled loading. Fine-grained materials, such as this ferricrete material, commonly display a different response to coarse-grained materials as the modulus decreases with increasing stress level until a certain value is reached, after which it tends to increase slightly when a conditioning load stage has been passed (Theyse 2001).

The stiffness of the norite material stabilised with $2 \%$ and $4 \%$ under dynamic loading at wet and dry conditions when the material was compacted at $100 \%$ Modified AASHTO density compaction effort, as depicted in Figure 7.

The intention with the two points depicted in Figure 7 was to evaluate the effect of the variation in moisture, rather than to evaluate the quantity of the effect. The dynamic effective stiffness of the norite material stabilised with $2 \%$ cement content showed an increase of $97 \%$ from $52 \mathrm{MPa}$ to $98 \mathrm{MPa}$ in stiffness when the material deviated from wet to dry conditions. On the other hand, the dynamic effective stiffness of the norite material stabilised with $4 \%$

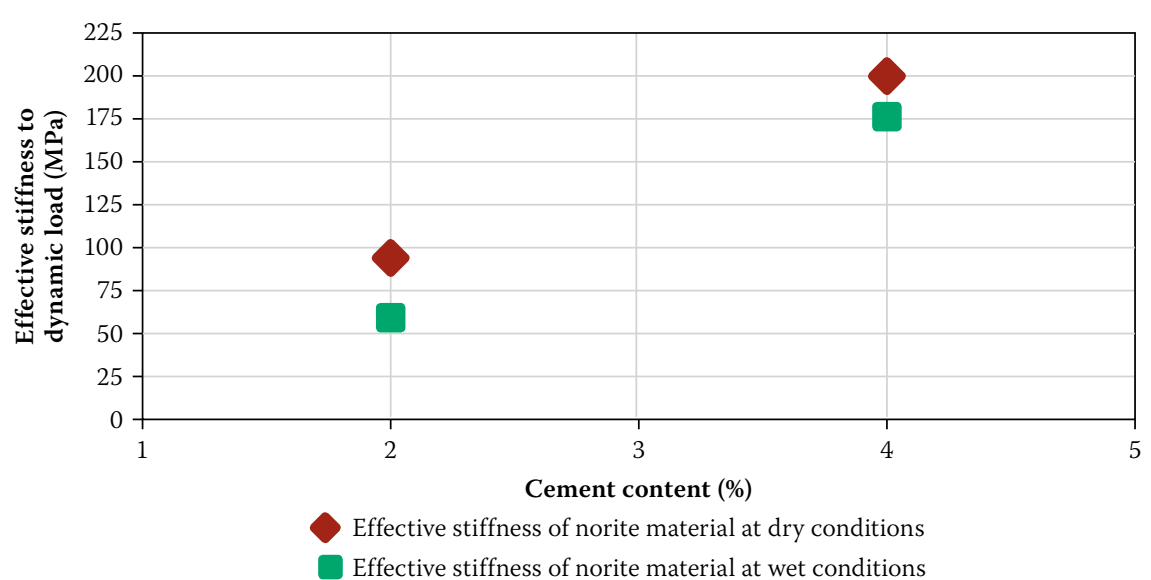

Figure 7 Dynamic effective stiffness at $100 \%$ Modified AASHTO density compaction effort in the variations of the conditions of the stabilised norite material

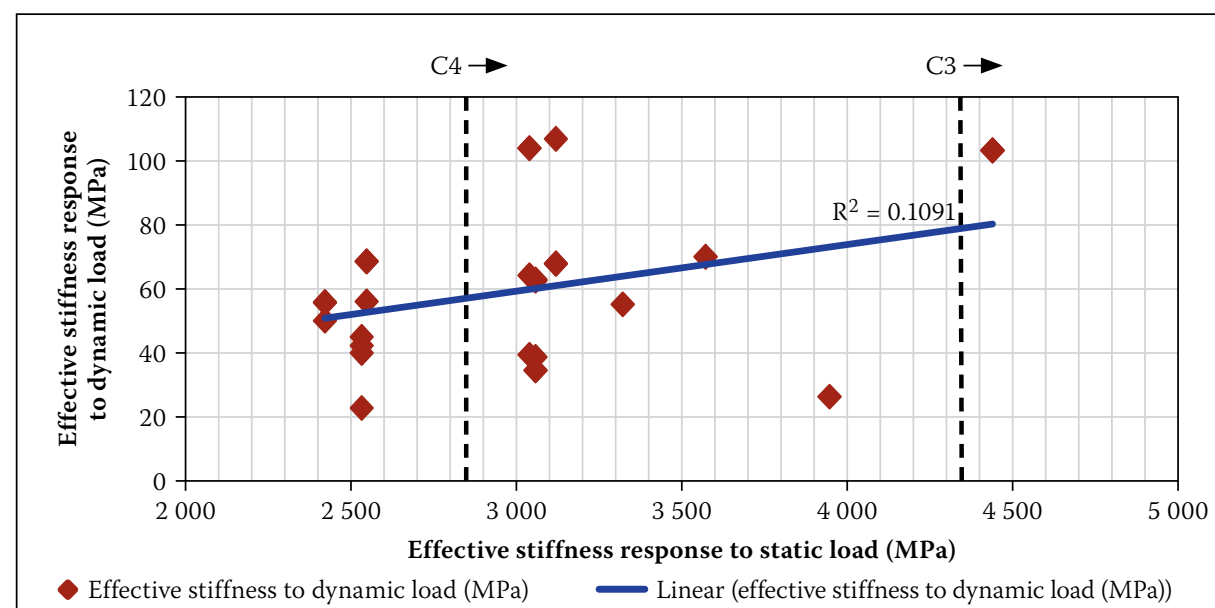

Figure 8 Relationship between effective stiffness response to dynamic load against static load

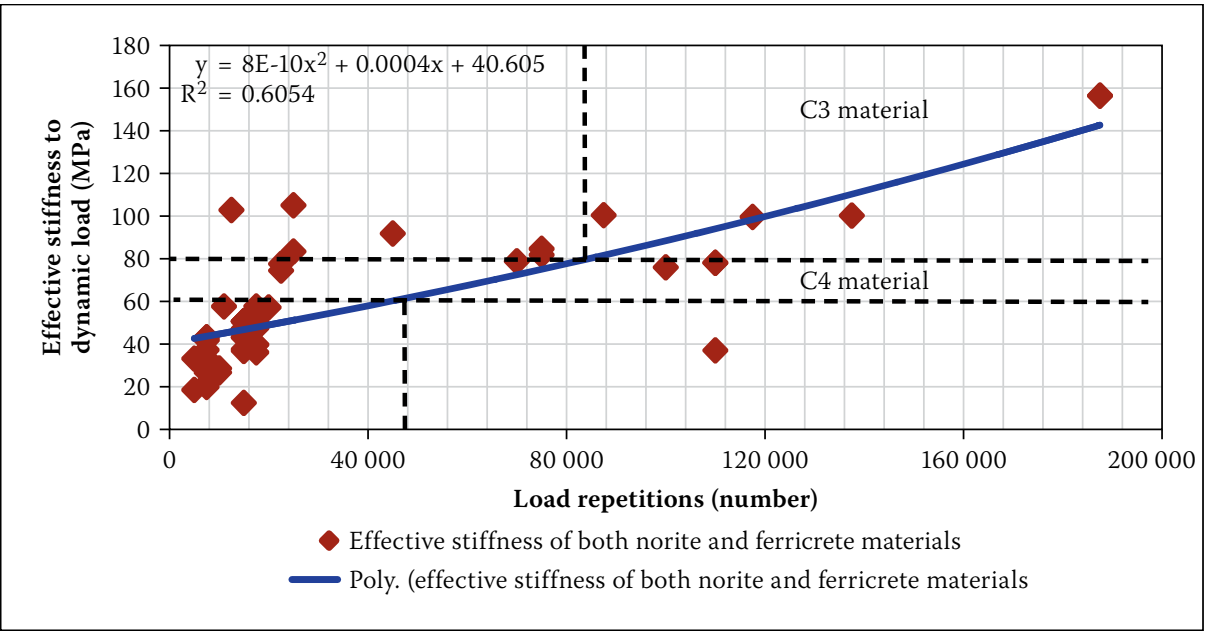

Figure 9 Relationship between the effective stiffness and load repetitions to dynamic load

content showed an increase of $30 \%$ from $170 \mathrm{MPa}$ to $200 \mathrm{MPa}$ in stiffness when the material deviated from wet to dry conditions. The dynamic effective stiffness of the norite material stabilised with $2 \%$ cement content showed an increase of $50 \%$ from $100 \mathrm{MPa}$ to $150 \mathrm{MPa}$ in the stiffness, and when stabilised with $4 \%$ cement content showed an increase of $100 \%$ from $150 \mathrm{MPa}$ to $300 \mathrm{MPa}$ in the stiffness when the material deviated from wet to dry conditions.
The stiffness results of the stabilised norite material response to dynamic load indicated that:

- Compaction improved the strength of material by increasing cohesion.

- Cement content increased rigidity of material to loading.

- The material still remained slightly sensitive to moisture.

A comparison of the static and dynamic effective stiffness of both the stabilised 
Table 5 Suggested values of the effective stiffness related to the $\mathrm{C} 4$ and $\mathrm{C} 3$ material strength

\begin{tabular}{|c|c|c|c|}
\hline \multirow{2}{*}{ Category } & \multicolumn{2}{|c|}{$\begin{array}{c}\text { Suggested stiffness of dynamic load } \\
\text { (minimum values) }\end{array}$} & $\begin{array}{c}\text { Static load } \\
\text { (minimum values) }\end{array}$ \\
\cline { 2 - 4 } & $\begin{array}{c}\text { Effective stiffness } \\
\text { (MPa) }\end{array}$ & $\begin{array}{c}\text { Load repetition } \\
\text { (number) }\end{array}$ & $\begin{array}{c}\text { Effective stiffness } \\
(\mathbf{M P a})\end{array}$ \\
\hline $\mathrm{C} 4$ & 60 & 47000 & 2860 \\
\hline $\mathrm{C} 3$ & 80 & 83300 & 4340 \\
\hline
\end{tabular}

norite and ferricrete materials in both wet and dry conditions is depicted in Figure 8.

The depiction in Figure 8 is related to the proposed stiffness of the $\mathrm{C} 4$ and $\mathrm{C} 3$ stabilised materials as proposed by Theyse et al (1996). For the determination of the C4 and C3 stabilised materials stiffness, effective stiffness of static loads of $2836 \mathrm{MPa}$ and $4297 \mathrm{MPa}$ which were derived from the minimum UCS value of $750 \mathrm{kPa}$ and $1500 \mathrm{kPa}$ respectively, were used to categorise the effective stiffness of the dynamic load. All the stiffness responses to dynamic load were plotted to determine a trend line to be used for the classification of the material, considering that stiffness did not correlate well with a regression coefficient of only 0.11 . This poor correlation indicated that the stiffness of both the stabilised ferricrete and materials could have been influenced by the variation in moisture and stabilisation, and also the potential of effective stiffness response versus static could possibly not have been a good correlation in terms of what it measured. Reading off from the regression line, it was discovered that the minimum effective dynamic stiffness values of approximately $60 \mathrm{MPa}$ and $80 \mathrm{MPa}$ may be for the C4 and C3 stabilised materials' strength respectively.

A comparison of the dynamic effective stiffness and load repetitions of both the stabilised norite and ferricrete materials in both wet and dry conditions are depicted in Figure 9.

In relating the minimum dynamic effective stiffness values obtained in Figure 8 , together with the load repetitions, the stiffness of both the norite and ferricrete materials in both wet and dry conditions were plotted against the number of load or stress repetitions which caused strain at break at the end of working strain and are depicted in Figure 9. Polynomial regression was used to determine the relationship between the effective stiffness to dynamic load and load repetitions. The dynamic effective stiffness correlated reasonably well with the regression coefficient of 0.61 . The expected load repetitions induced from dynamic load at the proposed minimum effective stiffness values of C4 and C3 materials were 47400 and 85500 respectively.
The suggested modelled values of the effective stiffness and number of load repetitions responding to dynamic load are presented in Table 5.

The values in Table 5 relate to the effective stiffness of the static load. Finally, it has to be mentioned that even though a sub-base layer may have an effective stiffness above the suggested values for $\mathrm{C} 4$ and $\mathrm{C} 3$, a number of load repetitions (stress) will be of impact because it will determine the fatigue phase of the sub-base layer.

\section{CONCLUSIONS}

A sub-base layer is fully functional when its properties are improved by stabilising the material to improve the layer's effective stiffness. The effect of dynamic loading on the response of this parameter of layer was of great concern, and an investigation was conducted to determine the response of a cement-stabilised layer by measuring the response to static and dynamic loading. The stiffness response to both dynamic and static loading was improved with the increase in cement content and compaction. The particles surrounding the granules acted as a bond, thus resulting in an increase in strength. The rate of increase in shear strength became greater as the cement content increased. It has been observed that an increase of $1 \%$ of cement content on the sub-base layer could increase the effective stiffness response to dynamic load proportionally, irrespective of the type of material, or the material's properties. This was because the layer damage induced by dynamic load primarily failed in the form of extensive micro cracks during the effective fatigue phase.

There was an increase in stiffness in all the norite and ferricrete materials when compaction was increased from $95 \%$ to $100 \%$ of maximum dry density. As the ferricrete material had higher fine material content and plasticity, it was noted that an increase in compaction effort improved the effective stiffness more than that of the norite material. The effective stiffness response to dynamic and static loads could be directionally proportional to the cohesion of the material particles and density of the layer.
Noting the relationship of the material response to static and dynamic loads for the determination of $\mathrm{C} 4$ and $\mathrm{C} 3$ material stiffness, the effective stiffness under static load, which was determined from the minimum UCS values of $750 \mathrm{MPa}$ and $1500 \mathrm{MPa}$, was used to categorise the effective stiffness of the dynamic load. It was found that the minimum effective stiffness and the load repetitions for the C4 and C3 materials evaluated under dynamic load could be developed with a low level of confidence at that stage because they correlated poorly. Although the parameters for the $\mathrm{C} 3$ and $\mathrm{C} 4$ materials response were developed, the material of the same properties as ferricrete material could reach a higher compressive stiffness at an early stage, as it has a short working strain and low load-carrying, while the material of a similar quality as the norite material could reach a constant working strain and still absorb more stress and load repetitions without a sign of decrease in stiffness. It meant that the norite material (C4) was expected to have a longer life span than the ferricrete material (C3) in worst conditions.

\section{ACKNOWLEDGEMENTS}

This paper is based on the work reported in the first author's Master of Technology (MTech) degree dissertation submitted to the Tshwane University of Technology. Tshwane University of Technology, the National Department of Transport's Northern Transportation Centre of Development, Geostrada Materials Engineering Laboratory and Aurecon are fully thanked for financial support. Tshwane University of Technology is also thanked for permission to publish this work.

\section{REFERENCES}

Brink, A B A 1985. Engineering Geology of Southern Africa, Vol. 4. Silverton: Building Publications. COLTO (Committee of Land Transport Officials) 1998. Standard Specifications for Road and Bridge Works for State Road Authorities. Pretoria: Department of Transport.

Cottrell, J R B H, Schinkel, T O \& Clark, M T 2003. A traffic data for mechanistic-empirical pavement designs. Virginia, US: Virginia Transport Research Council.

CSRA (Committee of State Road Authorities) 1986. TMH 1 - Standard Methods of Testing Road Construction Materials. Technical Methods for Highways, Pretoria: National Institute for Transport and Road Research, CSIR.

CSRA (Committee of State Road Authorities) 1986.

TRH 13 - Cementitious Stabilisers in Road

Construction. Technical Recommendations for Highways, Pretoria: Department of Transport. 
CSRA (Committee of State Road Authorities) 1985. TRH 14 - Guidelines for Road Construction Materials. Technical Recommendations for Highways, Pretoria: Department of Transport

De Beer, M 1985. Behaviour of cementitious subbase layers in bitumen base road structure. MEng dissertation (unpublished), Pretoria: University of Pretoria, South Africa.

De Beer, M 1990. Aspects of the design and behaviour of road structures incorporating light cementitious layers. PhD thesis (unpublished), Pretoria: University of Pretoria, South Africa.

De Beer M, Kannemeyer, L \& Fisher, C 1999. Towards improved mechanistic design of thin asphalt layer surfacing based on actual tyre/pavement contact Stress In Motion (SIM) data in South Africa. Proceedings, 7th Conference on Asphalt Pavements for Southern Africa (CAPSA), 29 August to 2 September 1999, Victoria Falls, Zimbabwe.

Jones, D, Paige-Green, P \& Prozzi, J 2001. Pozzolanic stabilisation of road pavement layers: A comparison between Californian and South African practice. Report CR 2001/17, Pretoria: Division of Roads and Transport Technology, CSIR.

Jordaan, G J 1994. The South African mechanistic pavement design method. Research Report RR 91/242, Pretoria: Department of Transport.

Kekana, P 2006. Traffic volume at the South African toll gates. MSc dissertation (unpublished), Cape Town: University of Cape Town.

Matheba, M J 2013. Behaviour of unconfined cemented materials under dynamic loading. MTech dissertation (unpublished), Pretoria: Tshwane University of Technology.

Natt, G S \& Joshi, R C 1984. Properties of cement and lime-fly ash stabilised aggregates. Transportation Research Record No. 998, Washington DC: Transportation Research Board.

Paige-Green, P 1989. The influence of geotechnical properties on the performance of unpaved gravel wearing course materials. PhD thesis (unpublished), Pretoria: University of Pretoria.

Paige-Green, P \& Bam, A 1995. The hardness of gravel as an indicator of performance in unpaved roads. Research Report RR 93/560, Pretoria: Department of Transport.

Paige-Green, P \& Netterberg, F 2004. Cement stabilisation of road pavement materials laboratory testing programme - Phase 1 . Confidential Contract Report CR 2003/42, Pretoria: National Institute for Transport and Road Research, CSIR.

SABS (South African Bureau of Standards) 2001. SABS EN-197-1:2000. Cement - Part 1: Composition, Specifications and Conformity Criteria for Common Cements. Pretoria: SABS.

Sadzik, E (CSIR) 2004. Personal interview, Pretoria. (Notes are in the possession of the first author.)

SANRAL (South African National Roads Agency Limited) 2007. Revision of South African Pavement Design Method (SAPDM). Peer review of the documentations prepared for the revision of the South African Mechanistic Design Method, Publication 1998/009584/06, Pretoria: SANRAL.
Steyn, W J vd M, De Beer, M \& Du Preez, W 1999. Simulation of dynamic traffic loading for use in Accelerated Pavement Testing (APT). Report 99/057, Pretoria: National Institute for Transport and Road Research, CSIR.

Steyn, W J vd M \& Sadzik, E 2007. Application of the portable pavement seismic analysis (PPSA) for pavement analysis. Proceedings, 26th Southern African Transport Conference (SATC 2007), 9-12 July 2007, Pretoria

Theyse, H L, De Beer, M \& Rust, F C 1996. Overview of the South African Mechanistic Pavement Design Analysis Method. Divisional Publication DP-96/005, 75th Annual Meeting of the Transportation Research Board (TRB), National Research Council, Washington DC.

Theyse, H L 2001. The development of mechanisticempirical permanent sub-grade deformation model from simulator data. MEng dissertation (unpublished), Johannesburg: Rand Afrikaans University.

Theyse, H L, Maina, J W \& Kannemeyer, L 2007. Revision of the South African flexible pavement design method: Mechanistic-empirical component. Proceedings, 9th Conference on Asphalt Pavements for Southern Africa (CAPSA), 2-5 September 2007, Gaborone, Botswana, pp 256-292.

Van Wijk, A J, Hervey, J \& Hartman, A M 2007. Assessing material properties for pavement rehabilitation design. Proceedings, 9th Conference on Asphalt Pavements for Southern Africa (CAPSA), 2-5 September 2007, Gaborone, Botswana. 